\title{
Geological evidence of pre-2012 seismic events, Emilia-Romagna, Italy
}

\author{
Riccardo Caputo ${ }^{1,}$, Kyriaki Iordanidou ${ }^{2}$, Luca Minarelli ${ }^{1}$, Giorgos Papathanassiou ${ }^{2}$, Maria Eliana Poli ${ }^{3}$, \\ Dimitra Rapti-Caputo ${ }^{1}$, Sotirios Sboras ${ }^{1}$, Marco Stefani ${ }^{1}$, Adriano Zanferrari ${ }^{3}$
}

\author{
${ }^{1}$ Università di Ferrara, Dipartimento di Fisica e Scienze della Terra, Ferrara, Italy \\ ${ }^{2}$ Aristotle University of Thessaloniki, Department of Geology, Thessaloniki, Greece \\ ${ }^{3}$ Università di Udine, Sezione di Georisorse e Territorio, Udine, Italy
}

\author{
Article history \\ Received July 23, 2012; accepted August 24, 2012. \\ Subject classification: \\ Morphogenic earthquakes, Seismic hazard assessment, Historical seismicity.
}

\section{Introduction}

In May 2012, two moderate (-to-strong) earthquakes that were associated with a noticeable aftershock sequence affected the eastern sector of the Po Plain, Italy, in correspondence with a buried portion of the Apennines thrust belt. The Provinces of Ferrara, Modena and Bologna (Emilia Romagna Region), Mantua (Lombardy Region), and Rovigo (Veneto Region) were affected to different extents. The first shock $\left(\mathrm{M}_{\mathrm{L}} 5.9\right.$ according to the Istituto Nazionale di Geofisica e Vulcanologia (INGV; National Institute of Geophysics and Volcanology), and $\mathrm{M}_{\mathrm{W}} 6.1$ according to the US Geological Service) occurred on May 20, 2012, at 2:03 a.m. (GMT); this was the strongest of the sequence, and it was followed by several aftershocks (up to $M_{L}$ 5.1). This first event produced secondary ground deformation effects, which were mainly associated with liquefaction phenomena that were spread across the broader epicentral region, and particularly in the western sector of the Ferrara Province [Papathanassiou et al. 2012, this volume].

A few weeks after the earthquake, a paleoseismological trench was excavated south of San Carlo village, where earthquake-induced effects were widely documented. This report presents the preliminary results of the paleoseismological investigation and documents the occurrence in the same area of paleo-events older than the May 2012 earthquakes.

\section{Geomorphical and paleogeographic framework}

In the investigated area, the liquefaction process, the locally associated surface fracturing, and the sand ejection that were induced by the May 20, 2012, earthquake were concentrated along an elongated topographic rise (Figure 1) that stretched from the villages of Sant'Agostino to Vigarano Mainarda, in the south-western portion of the Ferrara Province [Papathanassiou et al. 2012]. This geomorphological feature corresponds to a sedimentary body that had been accumulated by an abandoned reach of the Reno River that was active during Medieval and modern times [Cibin and Segadelli 2009].

The Reno River outflows from the highly erodible northern Apennines, and it is therefore very rich in sedimentary load. The Reno alluvial plain records major lateral gradients of subsidence, caused by both differential compaction [Carminati et al. 2003] and the persistent activity of blind faults, which characterize this sector of the buried Apennines accretionary wedge. The DInSAR results [Atzori et al. 2012] provided straightforward documentation regarding the creation of topographic gradients as a consequence of the May 2012 coseismic deformation, and strongly suggested the likely occurrence of cumulative effects.

The synergic role of fast subsidence and large sedimentary input have produced very high sedimentation rates locally and frequent changes in the fluvial drainage framework. The area has experienced great mobility of the rivers network, the evolution of which can be reconstructed and dated in great detail, through the correlation of the stratigraphicsedimentological evidence with a large amount of written historical information and accurate ancient maps [Bondesan 1989, MURST 1997, Castiglioni et al. 1999]. From the late Medieval times to the late XVIII century, the Reno water was neither able to reach the Adriatic Sea nor to directly flow into the Po River, which was running ca. $10 \mathrm{~km}$ to the north of the study area; therefore, wide inland marshes and lakes were generated. These fresh-water environments were mainly developed in the fast subsiding areas between Ferrara and Bologna [Bondesan 1989].

The depositional evolution of the region was punctuated by a large number of failed artificial embankments and land reclamation efforts. The almost rectilinear geometry of the investigated paleo-channel (Figure 1) was influenced by frequent human intervention. However, it was only at the end of the XVIII century that the Reno River was success- 


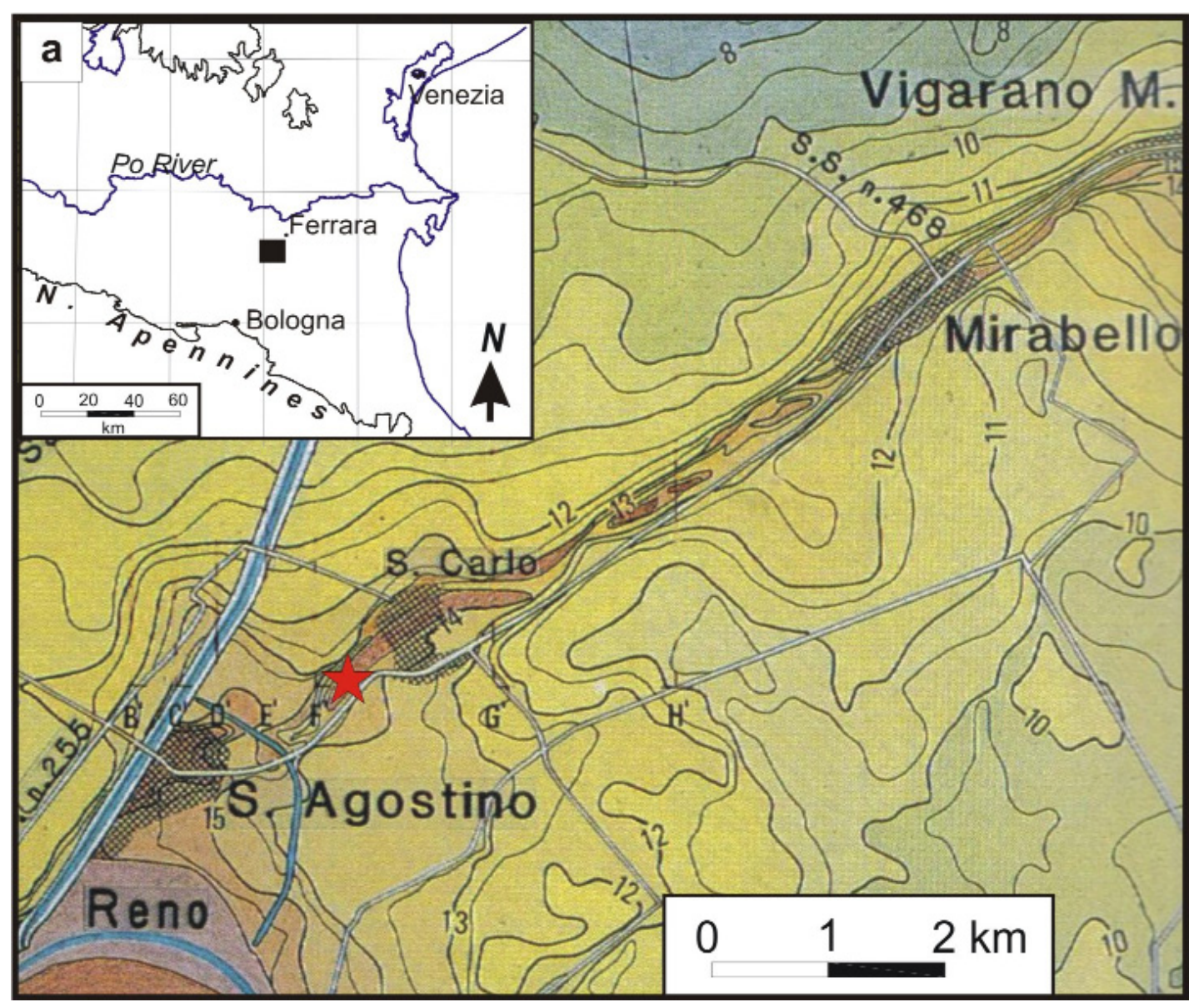

Figure 1. Detailed topographic map (contours every $0.5 \mathrm{~m}$; different colors indicate altitudes as meters a.s.1.) of the western Ferrara Province, showing the relief associated with the paleo-reach of the Reno River from Sant'Agostino to Vigarano Mainarda. Modified from Graziani et al. [1992]. Red star, location of the trench investigated in this study $\left(44^{\circ} 47^{\prime} 56^{\prime \prime} \mathrm{N}, 11^{\circ} 24^{\prime} 05^{\prime \prime} \mathrm{E}\right)$; black box in (a), location of the topographic map in northern Italy.

fully forced to reach the sea, through the pre-existing southern distributary channel of the Po River [Cremonini 1988]. The Reno water was diverted just to the south of the investigated site, and any water flowing northwards of Sant'Agostino was therefore impeded. The former channel dried up completely, thus preserving well its depositional morphology, only locally obliterated by modern anthropic activities. The elevated areas corresponded to the levee sedimentary bodies, and these were characterized by the availability of phreatic waters and by the relatively good geotechnical properties for building. Accordingly, several villages were located along the former channel, and the Modena-Ferrara road was constructed along the same path. The former levee crests are still often $5 \mathrm{~m}$ higher than the surrounding interchannel depressions. Large topographic gradients still characterize the former channel area, which induced a lateral load gradient that had a major role in the coseismic liquefaction dynamics [Papathanassiou et al. 2012].

\section{The trench site}

As a consequence of the May 20, 2012, earthquake, south of San Carlo village the eastern levee of the paleoReno River was largely affected by a system of parallel ground ruptures, These developed with a systematic NE-SW direction, forming a complex system of overstepping and partly overlapping fractures. Single features were several decameters long, showing extensional kinematics locally (i.e., openings up to $35 \mathrm{~cm}$ ) and / or vertical displacement (up to 30 $\mathrm{cm}$ ), with either the SE or NW sides down. In sectors characterized by fractures with antithetic normal kinematics, 110-m-wide grabens were formed (Figure 2). In some cases, the visible depth of the furrows was several meters.

The a-priori target of the present study was to document the possible occurrence of past liquefaction phenomena that are older than the 2012 earthquake. The choice of the best site for paleoseismological trenching was based on (i) logistic criteria, with the land uncultivated and thus easily accessible for the operating machines; (ii) the preserved original morphology of the paleo-Reno levee; (iii) the absence of any buildings in the surroundings that could possibly induce differential anthropogenic load, thus interfering with the underlying liquefied layer(s); and (iv) the lack of modern sand ejection, despite the impressive ground ruptures. The excavated trench (latitude, $44^{\circ} 47^{\prime} 56^{\prime \prime} \mathrm{N}$; longitude, $11^{\circ} 24^{\prime} 05^{\prime \prime E}$ ) was oriented SE-NW, so it was perpendicular to the eastern levee of the abandoned river, and it was more than $55 \mathrm{~m}$ long, $5 \mathrm{~m}$ to $8 \mathrm{~m}$ wide, and $5 \mathrm{~m}$ to $5.5 \mathrm{~m}$ deep. 


\section{Depositional features observed in the trench}

Due to the abandonment of this Reno River reach, which was dated to the second half of the XVIII century, the investigated sector had preserved the geomorphic expression of the sedimentary bodies well. The channel sand unit was generally $100 \mathrm{~m}$ to $120 \mathrm{~m}$ wide, whereas each levee exceeded $500 \mathrm{~m}$ in width. Immediately to the west of the excavated paleoseismological trench, the very late channel position was still marked by a topographic depression. This was flanked on both sides by the natural levee elevations. At this point, the river was flowing with a slightly curving path, with the concavity to the east, and this is well recorded by the depositional geometry observed in the trench. The explorative excavation cut across the internal portion of the eastern levee surface, dipping towards the NW, with an average dip of about $15^{\circ}$ to $20^{\circ}$ (Figure 3). Although more subtle, a slightly older channel structure was visible to the east of the trench, partially buried by more recent levee and crevasse splay sands.

The trench excavation provided a valuable insight into the fluvial channel and the natural levee sedimentation. Three major sedimentological units were recognized:

(a) A comparatively 'old' unit (assumed as Medieval in age, from its stratigraphic position) that was visible in the lower south-eastern portion of the trench, and this consisted of a distal levee or proximal alluvial plain silts and silty clays, with graded overbank beds, which were often partially amalgamated by bioturbation. Ancient root structures, pedogenetic alteration evidence, and traces of agricultural activity were visible, alongside a few ceramic fragments. The permeability of the unit was lower than that of the younger ones.

(b) The main portion of the trench walls consisted of proximal levee sands and sandy silts, which often showed direct gradation and tractive lamination structures. The older

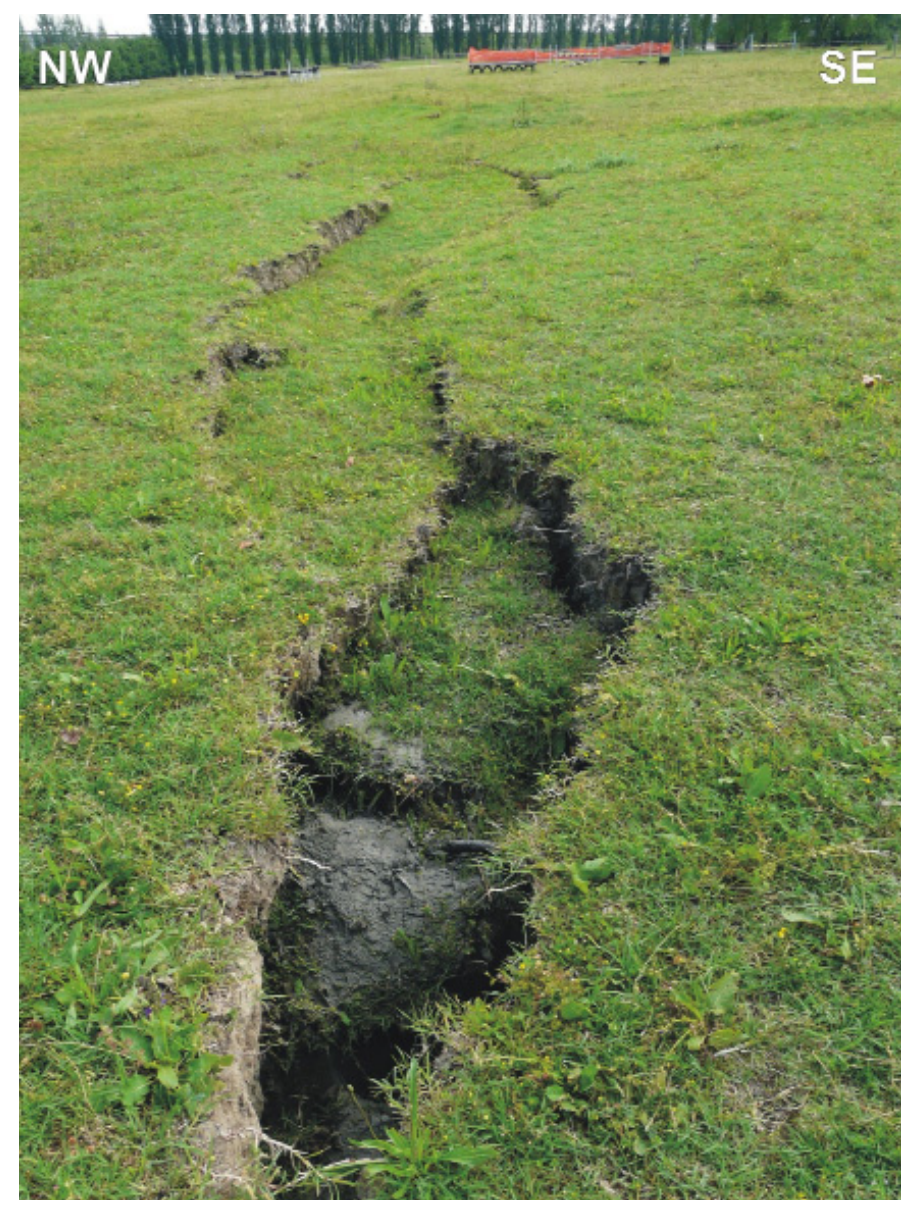

Figure 2. Example of a small-scale graben formed along the fracture system that developed on the levee of the paleo-reach of the Reno River, close to the trench site. See Figure 1 for location.

portion of the unit documented a fluvial channel at the south-east of the trench; however, most of the unit was formed by younger sediments, coeval to the western channel deposits. The cross-laminations of this young sediment pro-

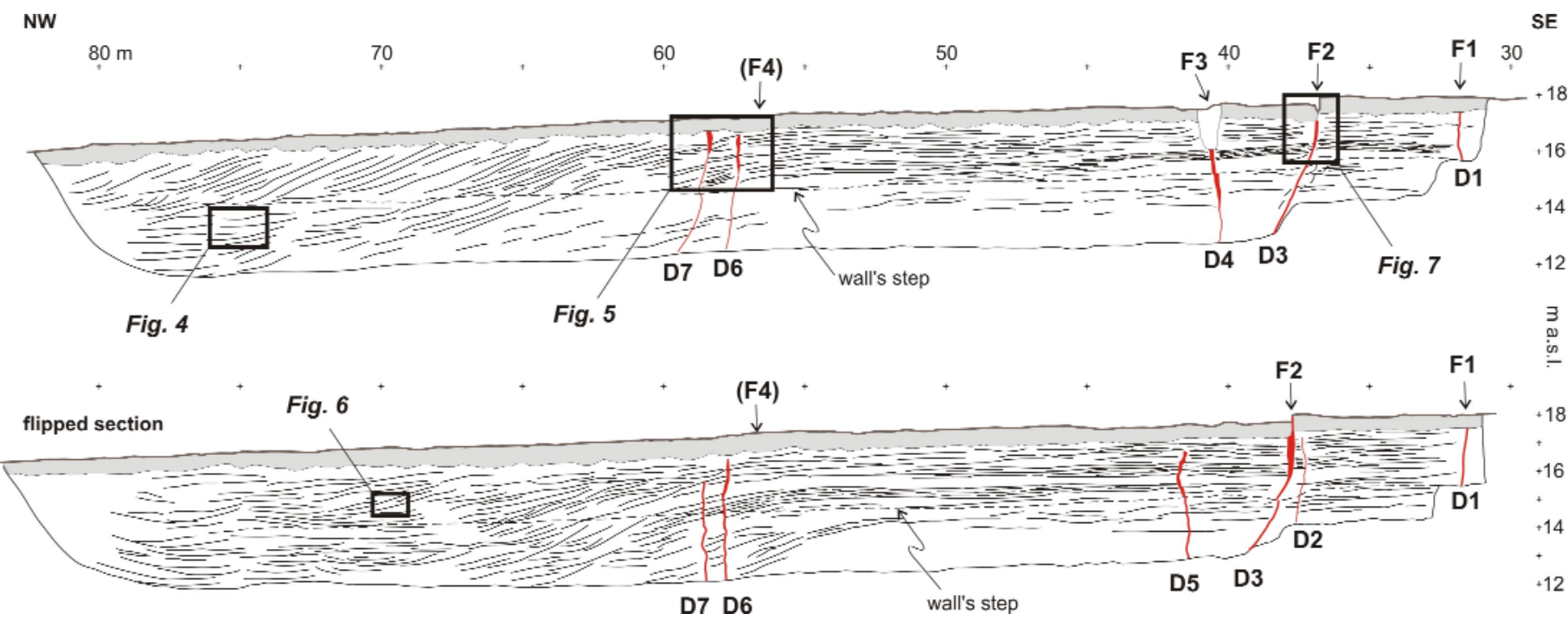

Figure 3. Trench logs (SW wall flipped) showing the intersection of the ground ruptures (F) with the walls, the location of the sand-filled dikes (D), and the stratigraphic framework. The three-dimensional view of the dikes in the trench allows recognition of D4 and D5 as two distinct overstepping structures. The vertical scale is in meters a.s.l. No vertical exaggeration was used. 


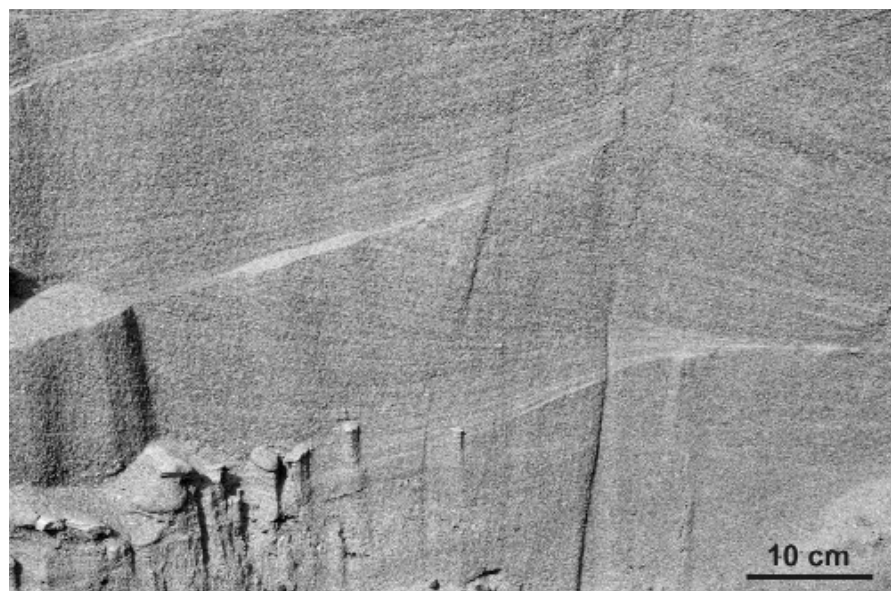

Figure 4. Example of festoon cross-stratification within the channel sediments that records dispersed turbulence flows, with a dominant direction towards the northeast, sub-parallel to the channel trend. See Figure 3 for location in the trench wall.

vided a record flux direction towards the east. In the western portion of the trench walls, the depositional beds dip into, and interdigitate with, channel infilling sands, although the contact was disturbed by compaction deformation and ancient liquefaction disturbance. The upper part of the unit was strongly perturbed by modern agriculture procedures. A phreatic nappe was well developed within this unit at shallow levels, until the river flow ended.

(c) The channel sediments consisted of medium sand (about $1 \mathrm{~mm}$ in maximum diameter), showing festoon crossstratification (Figure 4), which recorded dispersed turbulence flows, with a dominant direction towards the northeast, subparallel to the channel trend. The sands encompassed flat argillaceous rip-up intraclasts, rounded armored mud balls, wood rests, and brick fragments, also of conspicuous dimensions and of local provenance. Large fragments of the levee silt deposits (up to ca. $2 \mathrm{~m}$ in elongation) repeatedly fell into the channel sands, due to the gravitational sliding of the river bank, which was probably associated with past shaking events. The highly permeable sand unit underlying the river bottom was obviously saturated with water until the diversion of the river.

\section{Paleoseismically induced features}

The excavation area was affected by some major ground ruptures, and their intersection points with the trench are depicted in Figure 1. We documented the occurrence of seismically induced features (e.g., seismites) that well predated the May 2012 fractures (in both walls of the trench). The nat-

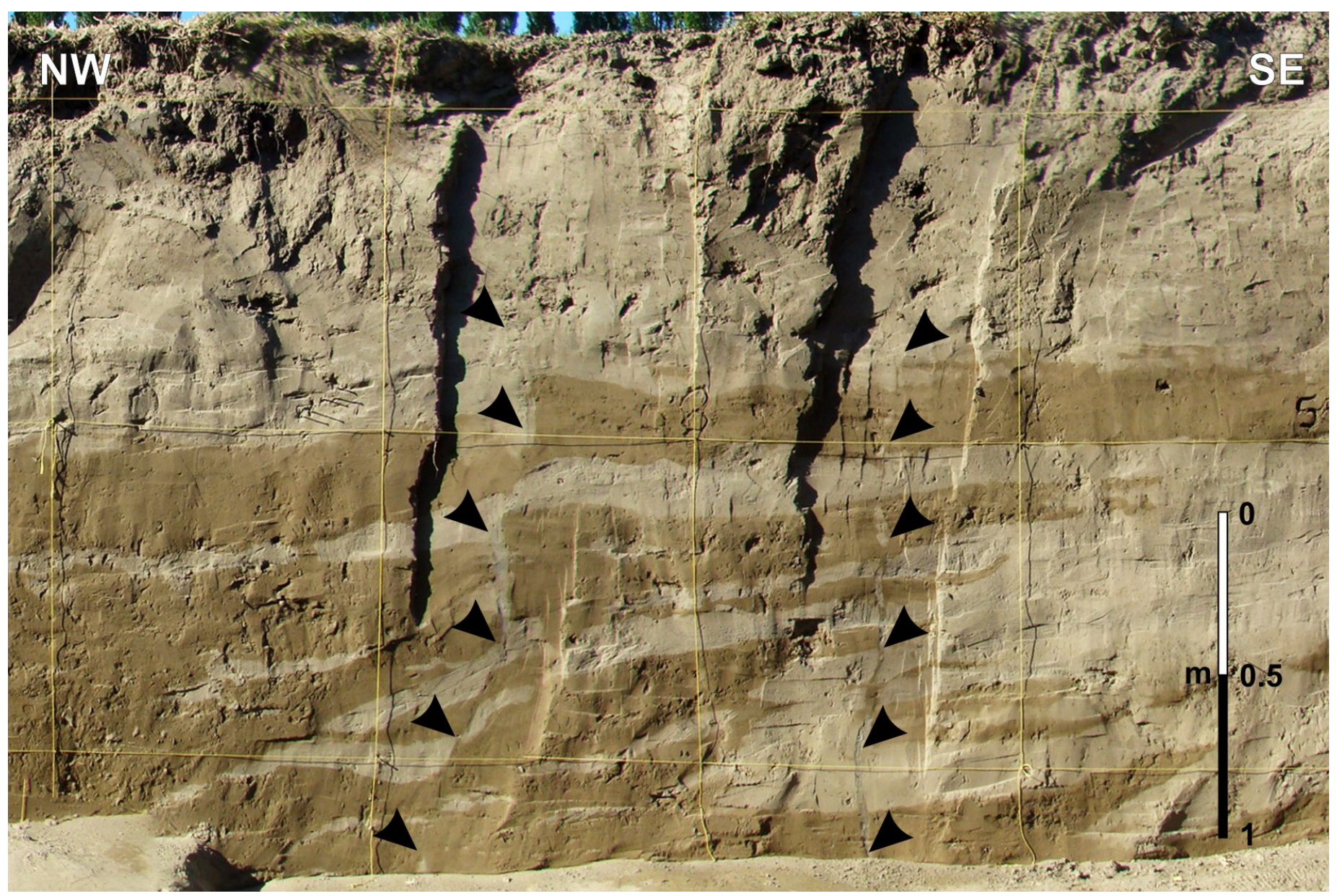

Figure 5. Example of sand-filled dikes (D6 and D7 in the northeastern wall) that affected the levee-associated deposits and interrupted below the ploughed layer. See Figure 3 for location in the trench wall. 


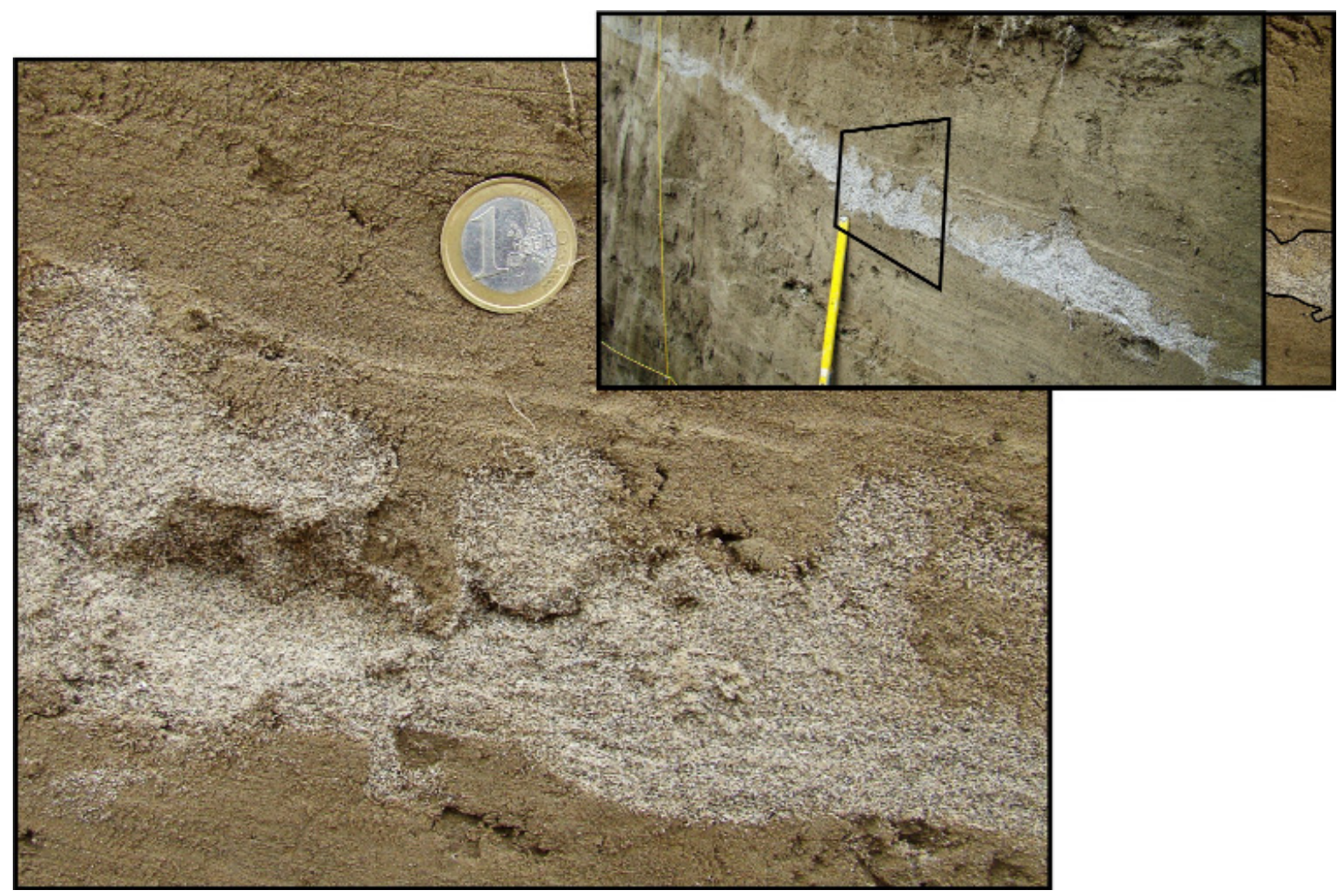

Figure 6. Example of 'load structures' that affect the channel-related deposits. See Figure 3 for location in the trench wall.

ural levee body is clearly cross-cut by several sand-filled dikes (Figures 3, 5), while local deformation phenomena (i.e., 'load structures' and large sliding blocks) were also well recorded, especially at the boundary between the channel and the levee sedimentary bodies (Figure 6).

All of the dikes observed were almost perpendicular to the trench walls and at high-to-normal angles with respect to the depositional layering. Dikes were mainly formed as extensional joints that were characterized by an opening of up to $10 \mathrm{~cm}$ to $12 \mathrm{~cm}$, although some subordinate portion of their width could also be caused by lateral 'erosion' of the dike walls during the injection phase, as suggested by the local mismatch between the two walls. Dike D3 (Figure 3) was reactivated during the 2012 event, with a normal sense of shear and a maximum throw of ca. $15 \mathrm{~cm}$ (Figure 7), whereas dike D7 showed similar kinematics and a throw of ca. $20 \mathrm{~cm}$, but was not visibly affected by the last earthquake.

The trench provided a three-dimensional view of some of the coseismic features, thus emphasizing the typical geometrical complexities of the fracture systems developed within a mainly extensional stress field at their early development stage. Both horizontal and vertical en-echelon stepovers were observed. All of these structures are associated with the local and superficial tensile-stress field, and affected the levee due to a lateral spreading process [Papathanassiou et al. 2012]. The medium-to-coarse sand infilling of the dikes was injected from below and/ or from the side of the dikes. This latter flow direction was a secondary effect of the major vertical conduits that were induced by the lateral variability of the frac- tures. It is indeed unlikely that decameters-long fractures are characterized by a uniform opening throughout their length.

The source material of these dikes was from a deeper river-sand unit that was not reached by the trench excavation. The sedimentary level of the probable source was recognized using cone penetration tests that were carried out in the surrounding area, and cores drilled a few hundred meters away, in the same morphological, hydrogeological and stratigraphic setting of the trench. The source unit consisted of a medium-to-coarse sand layer that occurred at a depth of $7 \mathrm{~m}$ to $8 \mathrm{~m}$ from the surface, which varied in thickness between $1.5 \mathrm{~m}$ and $4 \mathrm{~m}$, and which probably recorded large crevasse splay and overbank flood episodes. Due to the stratigraphic setting and hydrogeological framework, the layer represents a semi-confined aquifer, which is characterized by a high degree of liquefaction susceptibility.

The topographic gradient towards the NW corresponded to the sedimentary inclined stratification of the underlying stratigraphic succession. Taking into account the gravitational genetic component of the stress tensor [Caputo 2005], this geometrical setting can generate a non-null shear-stress on the sedimentary surfaces. In the case of liquefaction, even a small component of shear stress easily overcomes the low resistance that characterizes the temporary fluid (i.e., viscous) behavior. This effect might be enough to trigger lateral sliding of the levee sediments. As a further consequence, subvertical extensional fractures parallel to the channel must form 'uphill' to enable the block motion. If the extensional structures are directly connected to the layer(s) where liquefaction occurs, then 


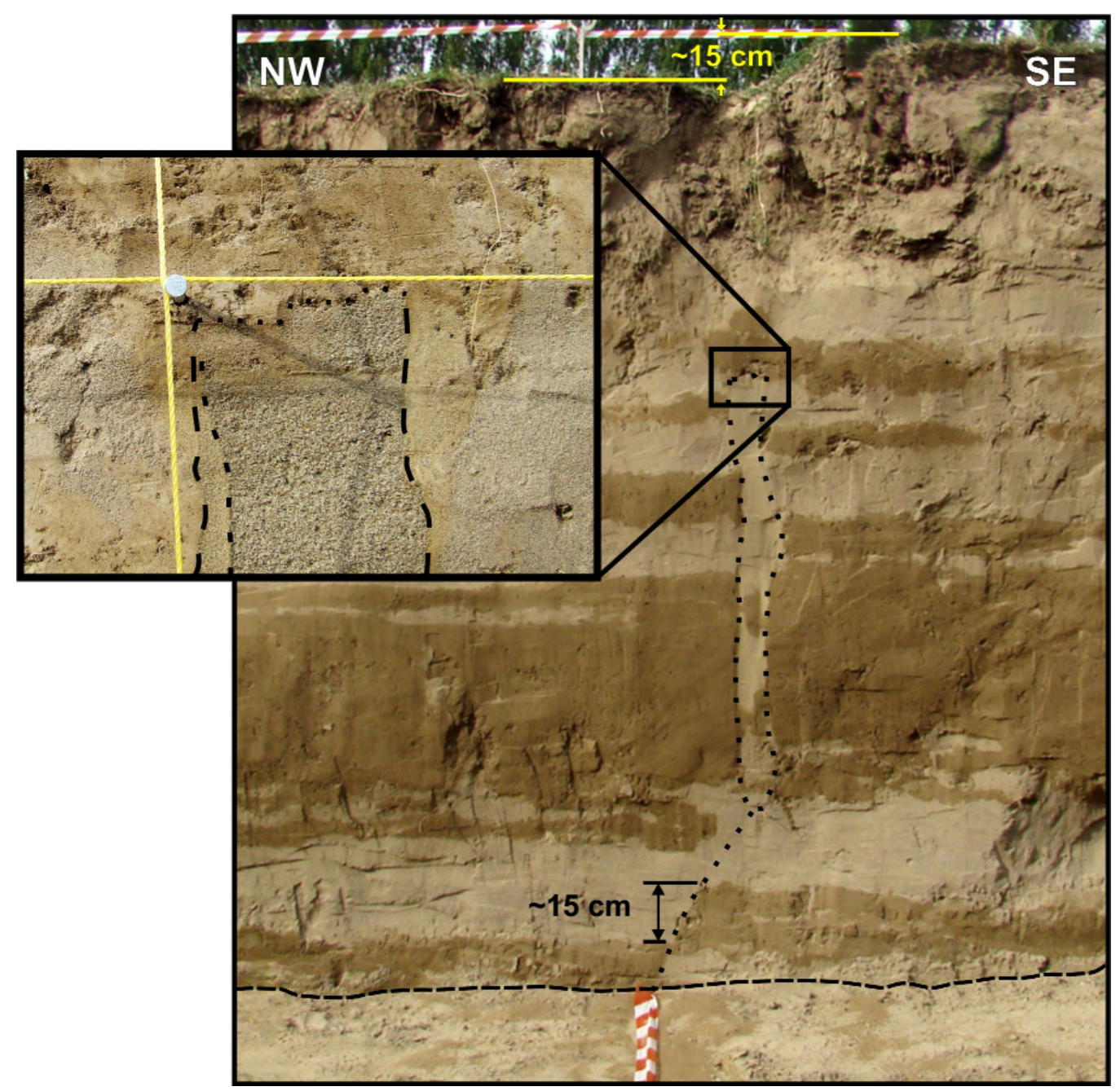

Figure 7. Example of a thick sand-filled dike (D3 on the northeastern wall) clearly sealed by younger sedimentary beds, thus emphasizing the occurrence of liquefaction events older than the May 2012 earthquake. See Figure 3 for location in the trench wall.

water and sand can be ejected up to the surface.

There was diffuse lateral spreading along the levees of the paleo-channel from Sant'Agostino to Mirabello during the May 2012 event [Papathanassiou et al. 2012] and this was responsible for the ground ruptures that were mapped at the trench site. However, for several reasons, none of the sandinfilled dikes observed in the trench could be related to the 2012 earthquake. First, they were systematically sealed at some depth from the surface, and generally below the ploughed layer (ca. $60 \mathrm{~cm}$ deep) or at a deeper level below the sedimentary beds, as shown in Figure 7. A similar setting clearly implies the occurrence of one or more complete sequences of processes (i.e., liquefaction, lateral spreading, fracture propagation, sand injection) that predated the accumulation of the unaffected overlying sediments.

Another documentation of the nature of the dikes relating to pre-2012 events is the lack of any sediment ejection along the ground rupture F2 during the recent earthquake, corresponding to dike D3 (Figure 3). Indeed, dike D3 probably represented a weakness zone and it was thus easily reactivated, generating an opening of a few centimeters and a throw of ca. $15 \mathrm{~cm}$. Despite the occurrence of a 10-cm-thick sandy dike just $1 \mathrm{~m}$ below the ground surface (Figure 7) and the available direct connection with the atmosphere (Figure 3, fracture F3), the lack of sand outflow confirms that the infilling material was injected during a previous liquefaction event.

Other evidence that the area was affected by older earthquakes is seen in the 'load structures' observed along the walls of the trench. Figure 6 shows a typical example of such structures, where the highly irregular interface between the coarse-grained sand and the overlying clayey silt are certainly not sedimentary in origin, and are likely to be due to shaking that triggered the incipient mixing phenomenon of the two materials, which was characterized by different densities and rheological behavior [e.g., Owen 2003]. Considering the burial depth of occurrence and the present-day lower water table level, in May 2012 this material was completely drained. In contrast, up to the XVIII century, when this reach of the Reno River was active, the higher piezometric level allowed a more viscous behavior of these layers.

Finally, in the transition sedimentary belt between the levee edge and the paleo-channel (i.e., in correspondence with the internal slope of the paleo-river bank), large clayeysilty blocks (as wide as ca. $2 \mathrm{~m}$ and up to $40 \mathrm{~cm}$ high) slide 
downwards into the active channel deposits. Although these features are basically gravitational in origin, the strong ground shaking possibly triggered the process.

\section{Concluding remarks}

Historical information suggests that the study sediments predominantly accumulated during the late XV and the XVI centuries [Bondesan 1989]. On the other hand, the historical seismicity of the area is relatively well known [Locati et al. 2011], and shows the occurrence of two moderate events since the XVI century (the Ferrara 1570 and Argenta 1624 earthquakes) [Guidoboni 1994, Guidoboni et al. 2007]. During both events, spectacular liquefaction phenomena were reported in adjacent urbanized areas (e.g., in Ferrara). Both historical earthquakes could have been the causative events of the liquefaction phenomena observed in the paleoseismological trench, although possible older events not included in the historical seismic catalogs should not be neglected. Indeed, as the Reno River was flowing at that time, and as both events were concomitant to rainy periods (November 17 and March 19, respectively), the water table of the superficial aquifer, namely A0 [Regione Emilia-Romagna and ENI-AGIP 1998] was certainly much shallower than at present, and was also under greater hydrostatic pressure. These effects facilitated the liquefaction process and the consequent lateral spreading, affecting the levee, its fracturing, and the sand ejection. In contrast, during the 2012 seismic event, the water table was deeper than before, due to both the complete abandonment of this reach of the Reno River and the seasonal effects (drier May period). Accordingly, the hydrogeological conditions were manifestly sufficient to cause liquefaction at some depth and to trigger some lateral spreading, although not enough to eject the liquefied sand up to the surface in this study trench.

Acknowledgements. Our thanks go to the Municipality of Sant'Agostino, and particularly to the Major, Fabrizio Toselli, for providing technical and logistic support, and to the owner of the trench site (Mr. Giuseppe Fortini) for permitting the excavation. Our thanks also go to Servizio Geologico, Sismico e dei Suoli, Regione Emilia-Romagna, for providing access to the sedimentary cores drilled near the investigated area, and to Marco Bondesan for fruitful discussions.

\section{References}

Atzori, S., J. Merryman Boncori, G. Pezzo, C. Tolomei and S. Salvi (2012). Secondo Report analisi dati SAR e modellazione della sorgente del terremoto dell'Emilia, INGV.

Bondesan, M. (1989). Evoluzione geomorfologica e idrografica della pianura ferrarese, Terre ed Acqua, Corbo Editore, 14-20.

Caputo, R. (2005) Stress variability and brittle tectonic structures, Earth Sci. Rev., 70, 103-127.

Carminati, E., G. Martinelli and P. Severi (2003). Influence of glacial cycles and tectonics on natural subsidence in the Po
Plain (northern Italy): insights from ${ }^{14} \mathrm{C}$ ages, Geochem. Geophy. Geosy., 4, 1-14; doi:10.1029/2002GC000481.

Castiglioni, G., A. Biancotti, M. Bondesan, G.C. Cortemiglia, C. Elmi, V. Favero, G. Gasperi, G. Marchetti, G. Orombelli, G.B. Pellegrini and C. Tellini (1999). Geomorphological map of the Po Plain, Italy, at a scale of 1:250.000, Earth Surf. Proc. Land., 24, 1115-1120.

Cibin, U., and S. Segadelli, eds. (2009). Note Illustrative della Carta Geologica d'Italia alla scala 1/ 50 000, Foglio 203 Poggio Renatico, ISPRA, Servizio Geologico d'Italia, 104 pp.

Cremonini, S. (1988). Specificità dell'Alto Ferrarese nella problematica evolutiva dell'antica idrografia padana inferiore, In: Bondeno ed il suo Territorio dalle Origini al Rinascimento, Grafis Ed., Bologna, 17-24.

Graziani, S., R. Ferri and M. Bondesan (1992). Aspetti geomorfologici e problemi paleogeografici della zona fra Bondeno, Finale Emilia e Mirabello nel quadro degli antichi domini idrografici del Secchia, del Panaro e del Reno, In: S. Gelichi (ed.), Un mito e un territorio: Ansalaregina e l'Alto Ferrarese nel Medioevo, All'Insegna del Giglio, Firenze, 13-44.

Guidoboni, E. (1994). Riti di calamità: terremoti a Ferrara nel 1570-74, Quad. Storici, 55, 107-135.

Guidoboni, E., G. Ferrari, D. Mariotti, A. Comastri, G. Tarabusi and G. Valensise (2007). Catalogue of Strong Earthquakes in Italy from 461 B.C. to 1997 and in the Mediterranean area, from 760 B.C. to 1500. An Advanced Laboratory of Historical Seismology; http: / / storing.ingv. it/cfti4med/

Locati, M., R. Camassi and M. Stucchi, eds. (2011). DBMI11, la versione 2011 del Database Macrosismico Italiano, Milano/Bologna; http:/ / emidius.mi.ingv.it/DBMI11

MURST (1997). Geomorphological Map of the Po Plain, 3 sheets, scale 1:250.000, S.EL.CA., Firenze.

Owen, G. (2003). Load structures: gravity-driven sediment mobilization in the shallow subsurface, Geol. Soc. London, 216, 21-34.

Papathanassiou, G., R. Caputo and D. Rapti-Caputo (2012). Liquefaction phenomena along the paleo-Reno River caused by the May 20, 2012, Emilia (northern Italy) earthquake, Annals of Geophysics, 55 (4); doi:10.4401/ag-6147.

Regione Emilia-Romagna and ENI-AGIP (1998). Riserve idriche sotterranee della Regione Emilia-Romagna, G. Di Dio (ed.), S.EL.CA., Firenze, 120 pp.

\footnotetext{
${ }^{\star}$ Corresponding author: Riccardo Caputo,

Università di Ferrara, Dipartimento di Fisica e Scienze della Terra, Ferrara, Italy; email: rcaputo@unife.it.

(C) 2012 by the Istituto Nazionale di Geofisica e Vulcanologia. All rights reserved.
} 